\title{
Should I stay or should I go? A prospective investigation examining individual factors impacting employment status among individuals with multiple sclerosis (MS)
}

\author{
Lauren B. Strober ${ }^{\mathrm{a}, \mathrm{b}, *}$, Nancy Chiaravalloti ${ }^{\mathrm{a}, \mathrm{b}}$ and John DeLuca ${ }^{\mathrm{a}, \mathrm{b}}$ \\ ${ }^{a}$ Kessler Foundation, East Hanover, NJ, USA \\ ${ }^{\mathrm{b}}$ Department of Physical Medicine and Rehabilitation, Rutgers, State University of New Jersey- \\ New Jersey Medical School, Newark, NJ, USA
}

Received 5 July 2016

Accepted 8 May 2017

\begin{abstract}
.
BACKGROUND: Rates of unemployment among individuals with multiple sclerosis (MS) are as high as $80 \%$. While several factors for such high rates of unemployment have been identified, they do not account for the majority of the variance.

OBJECTIVE: This study examines person-specific factors such as personality and coping, which may better account for individuals leaving the workforce.

METHOD: Forty individuals with MS (20 considering reducing work hours or leaving the workforce and 20 remaining employed) were matched on age, gender, education, disease duration, and disease course, and administered a comprehensive survey of factors purported to be related to employment status.

RESULTS: Based on multiple, logistic regression analyses certain disease factors and person-specific factors differentiate those who are considering leaving work or reducing work hours and those staying employed. In particular, those expressing the need to reduce work hours or leaving the workforce reported more fatigue, anxiety, depression, and use of behavioral disengagement as a means of coping. In contrast, those staying employed reported greater levels of extraversion, self-efficacy, and use of humor as a means of coping. Together, fatigue, use of humor, and use of behavioral disengagement as a means of coping were the most significant factors, accounting for $44 \%$ of the variance.

CONCLUSIONS: Findings suggest that greater consideration be given to these factors and that interventions tailored to address these factors may assist individuals with MS staying employed and/or making appropriate accommodations.
\end{abstract}

Keywords: Employment decision, personality, self-efficacy, coping, depression

\section{Introduction}

Multiple sclerosis (MS), a demyelinating disease of the central nervous system (CNS), is the number

*Address for correspondence: Lauren B. Strober, 120 Eagle Rock Avenue, Suite 100, East Hanover, NJ 07936, USA. Tel.: +1973 324 8459; E-mail: 1strober@kesslerfoundation.org. one cause of neurological disability among young women and the second leading cause among young men [1], affecting approximately 400,000 individuals in the United States [2]. Multiple sclerosis affects women anywhere from two to three times as often as men [3], with an age of diagnosis ranging from 20 to 50 years of age and a mean age of onset of 33 years of age [4]. Given the age of onset, individuals with MS 
are typically in the prime of their careers and making important decisions regarding career and family. However, it is well appreciated that MS has a significant impact on individuals' social, familial, and occupational roles. In fact, the rate of unemployment in MS ranges from $60 \%$ to $80 \%$, with reports that approximately only $30 \%$ to $45 \%$ of individuals with MS are employed at any given time [5-9]. These rates are in stark contrast to reports that approximately $90 \%$ to $96 \%$ of individuals with MS are gainfully employed prior to their diagnosis $[9,10]$.

Numerous investigations that have examined the factors associated with unemployment in MS have found female gender, age, less education, and greater disability to be significant predictors [11]. Individuals with a progressive course are also more likely to be unemployed than those with a relapsing-remitting course [9]. Other factors shown to influence rates of unemployment include primary symptoms associated with MS such as poor balance and difficulty walking [12], bladder/bowel incontinence, and heat sensitivity [8]. Symptoms such as fatigue [5, 13], and cognitive difficulties $[8,14-16]$ are also reported as significant contributors; with fatigue likely being the greatest culprit. Cognitive impairment, particularly deficits in information processing speed and memory are also associated with leaving the workforce or sustaining changes in work status [14, 17, 18]. A comprehensive review of the literature from 2002-2011 confirm these findings, suggesting that fatigue, mobility impairments, cognitive impairment, lower education level, older age, and less prestige in past work are most accountable for the high rate of unemployment in MS [19].

While these symptoms of MS are certainly detrimental to one's functioning and have a direct impact on the individual, many have contended that they are insufficient in accounting for the strikingly high rates of unemployment in MS. In fact, in one of the earliest investigations, LaRocca and colleagues found that disease variables and demographics only accounted for $14 \%$ of the variance in predicting employment status [11]. They suggested that premorbid personality, coping style, characteristics of the workplace, and social support systems were likely to make a more significant contribution to the probability of an individual with MS staying employed. Nearly two decades later, Ratsep and colleagues asserted that psychosocial disability remains unexplained solely by disease severity or sociodemographic variables and recommended that more attention be given to the role that personality and coping has on the adjustment to MS [20]. In general, it is well established that personality, self-efficacy, and coping are intricately intertwined and, together, are likely to contribute to how one perceives and effectively manages a chronic illness, such as MS [21, 22]. Consideration of such factors is consistent with a biopsychosocial (BPS) approach, which emphasizes the role of the psychological and social factors as well as the biological in predicting health and outcomes. It has been argued that practitioners need to consider these factors simultaneously in order to fully appreciate the patient's subjective experience of their illness. Thus, while much is known about the contribution of demographics and disease variables, much less is known about the role personality has on MS, in general, but even less on how personality and related factors (e.g., selfefficacy, coping) may contribute to the high rates of unemployment in MS.

In general, personality has frequently been sought after as a determining factor of health and wellbeing. In particular, It has long been shown that neurotic-type personality characteristics or neuroticism is a predictor of somatization in the medically-ill and greater reports of pain [23] and cause of earlier mortality in the general population as well as the medically-ill [24]. Conscientiousness, on the other hand, has been found to be linked with healthier lifestyles and adherence to disease treatment and selfmanagement [25]. In working with cardiac patients, Denollet observed certain personality characteristics that seemed predictive of worse health status and outcomes. He coined this the so called "Distressed" or “Type D” Personality [26]. Individuals with Type D Personality are characterized as having a synergistic combination of higher levels of neuroticism and lower levels of extraversion or greater social discomfort [27]. It has been shown that individuals with a "Type D" personality have a worse prognosis, including a greater likelihood of myocardial infarction and mortality $[27,28]$. These individuals also engage in unhealthy behaviors, have lower perceived social support, and reduced quality of life [29]. This personality profile is also related to higher levels of depression and anxiety [30]. In MS, high levels of neuroticism and low levels of extraversion has also been found to be more predictive of reports of fatigue than physical impairment among individuals with MS [31]. Our recent work has also shown that personality, namely persistence or conscientiousness was a significant predictor of employment status, above and beyond disease severity and cognitive impairment [17]. However, this study and the remainder of investigations 
examining factors related to employment to date have been retrospective in nature. There are no studies in the existing literature that have examined the factors associated with leaving the workforce prior to an individual actually being unemployed - that is, what factors are at play as individuals are making the decision to leave the workforce? This is particularly important as it allows for a better determination of what symptoms or factors account for individuals feeling as if they have to reduce their hours or leave entirely. Retrospective studies also render it difficult to determine if the presence of identified factors associated with unemployment (e.g., depression, fatigue) were as great prior to leaving or are a consequence of not working. For instance, while depression and fatigue may predispose one to leave work, they may also be a consequence of being unemployed. In fact, increased depression, fatigue, and sleep disturbance are all known to occur among unemployed individuals in the general population [32]. Given the presence of these symptoms in MS, it is imperative to delineate whether or not these are the actual culprits that account for individuals leaving the workforce or simply an artifact of being unemployed, or both. Thus, the present study is the first investigation aimed at examining the factors associated with one's decision to leave the workforce prior to doing so, making it a very unique contribution to our understanding of employment challenges in persons with MS. Given the fact that disease and demographic variables are purported to be insufficient in accounting for such, the present investigation aims to determine the contribution that personality, self-efficacy, and coping have above and beyond the disease itself when making employment decisions.

\section{Methods}

\subsection{Participants}

All participants $(n=109)$ were diagnosed with clinically definite MS as verified by their neurologist and had enrolled in an investigation examining disease and person-specific factors associated with employment status in MS. Eligibility criteria included age ranging from 20 to 64, absence of other neurological disorders, and being presently employed. At the onset of the study, individuals reported whether or not they were considering reducing their hours or leaving the workforce altogether in the near future (i.e., within the upcoming year) due to their MS. Those individuals who were considering reducing their hours or leaving the workforce altogether due to their MS constituted the "considering group." Individuals who reported no intent to leave in the foreseeable future made up the "staying" group. Of this initial sample, 20 were in the "considering" group. Of the remaining 89 individuals who anticipated no change in their work status ("staying" group), 20 individuals were identified that were matched to the considering group on gender, age, education, disease course, and disease duration for comparison. Of the considering group, 18 (90\%) were employed full-time and 2 were employed part-time. Sixteen $(80 \%)$ of the staying group were employed full-time with 4 employed part-time (See Table 1).

All participants then completed an online survey consisting of questionnaires assessing work status and history, disease symptoms (e.g., fatigue), psychological functioning, personality, coping, selfefficacy, locus of control (LOC), and engagement in health promoting behaviors. All study procedures were approved by the Institutional Review Board of Kessler Foundation. Informed consent was obtained from all participants.

\subsection{Measures}

The Modified Fatigue Impact Scale (MFIS) was utilized to assess fatigue. The MFIS is modified form of the Fatigue Impact Scale [33] that is based on 21 items derived from interviews with MS patients concerning how fatigue impacts their lives. It consists of three subscales: physical, cognitive, and psychosocial functioning.

Depression was assessed by the Chicago Multiscale Depression Inventory (CMDI) [34], a self-report measure that was specifically designed to assess depression in MS and other medically-ill groups. It consists of three subscales: Evaluative, Mood, and Vegetative. Each subscale contains 14 items.

The State Trait Anxiety Inventory (STAI) [35] was used to assess state and trait anxiety. Individuals are asked to rate how the feel at this moment (state anxiety) as well as how they generally feel (trait anxiety) on 20 items assessing symptoms of anxiety.

Personality was assessed with the NEO-Five Factor Inventory-3 (NEO-FFI-3) [36], which is based on the five factor model of personality and includes subscales of Openness, Conscientiousness, Extraversion, Agreeableness, and Neuroticism. Individuals rate on a five-point Likert scale the extent to 
Table 1

Participant demographics

\begin{tabular}{lccc}
\hline Demographic & $\begin{array}{c}\text { Considering }(\mathrm{N}=20) \\
\text { Mean (S.D) or \# }\end{array}$ & $\begin{array}{c}\text { Staying }(\mathrm{N}=20) \\
\text { Mean (S.D.) or \# }\end{array}$ & t-test or $\chi^{2}$, sig. \\
\hline Gender & $19 \mathrm{~F} / 1 \mathrm{M}$ & $19 \mathrm{~F} / 1 \mathrm{M}$ & $\chi^{2}=0.360, p=0.548$ \\
Age & $44.90(9.65)$ & $43.60(8.91)$ & $\mathrm{t}(38)=0.443, p=0.661$ \\
Education & $15.75(2.36)$ & $16.25(1.71)$ & $\mathrm{t}(38)=-0.767, p=0.448$ \\
Disease Course & $20 \mathrm{RR}$ & $20 \mathrm{RR}$ & $\mathrm{N} / \mathrm{A}$ \\
Disease Duration (Years) & $5.54(5.57)$ & $5.68(5.19)$ & $\mathrm{t}(38)=-0.082, p=0.935$ \\
Employment Status & $18 \mathrm{FT} / 2 \mathrm{PT}$ & $16 \mathrm{FT} / 4 \mathrm{PT}$ & $\chi^{2}=0.784, p=0.376$ \\
\hline
\end{tabular}

which an attribute or behavioral tendency applies to them.

The COPE inventory [37] assesses different ways individuals respond to stress. It consists of five scales (of four items each) to measure problem-focused coping (Active Coping, Planning, Suppression of Competing Activities, Restraint Coping, Seeking of Instrumental Social Support) and five scales to measure emotion-focused coping (Seeking of Emotional Social Support, Positive Reinterpretation, Acceptance, Denial, Turning to Religion) and three less adaptive coping styles (Focus on and Venting of Emotions, Behavioral Disengagement, Mental Disengagement). Three items also measure Alcohol and Drug Use and four items assess use of Humor.

Self-efficacy was measured by the General SelfEfficacy Scale (GSE) [38] as well as the Disability Management Self-Efficacy Scale (DMSES) [39]. The latter was developed specifically for use in MS and assesses an individuals' perceived self-efficacy with regard to managing their MS and its interference on their everyday activities and overall well-being.

Locus of Control was assessed by the International Personality Item Pool Locus of Control scale (IPIPLOC) [40]. The IPIP-LOC assesses the degree to which individuals perceive having an external versus internal locus of control.

\subsection{Statistical analyses}

All statistical analyses were conducted using SPSS version 21.0. Initial comparisons of group means (Independent Students' $t$-test) and frequencies (Chi-square) were made between those considering leaving or reducing work hours and those who had no intent on changing their work status with regard to demographic factors. All analyses were conducted with raw scores of the measures. Based on these findings, six separate logistic regression analyses were then conducted with the following as independent variables: (1) Fatigue (Physical fatigue, Cognitive fatigue, Psychosocial fatigue, Total fatigue); (2) Depression (Evaluative); (3) Anxiety (Trait, State); (4) Self-efficacy and LOC (General self-efficacy, MS-specific self-efficacy); (5) Personality (Neuroticism, Extraversion); (6) Coping (Humor, Behavioral Disengagement). A subsequent final, stepwise logistic regression was conducted only with the variables found to be significant in these regression analyses to determine which factors were most predictive of individuals feeling as if they need to reduce work hours or leave the workforce.

\section{Results}

As stated, the purpose of the present investigation was to determine the contribution that person-specific factors (e.g., personality, self-efficacy, coping) have on employment decisions, above and beyond disease variables. Consistent with the matching of participants, there were no differences between the groups with regard to gender, age, education, disease course, or disease duration (in years). There were also no differences between the groups with regard to work status (i.e., full versus part time employment) (See Table 1).

Group demographics and differences ( $t$-test and effect size) on measures of fatigue, depression, anxiety, self-efficacy, locus of control, coping, and personality are provided in Table 2 for reference. Please note that the effect sizes are only provided for those factors that reached statistical significance of $p<0.05$.

Several regression analyses were conducted to determine which factors best differentiate those considering reducing work hours or leaving the workforce from those staying employed. In the first regression examining fatigue as an independent variable, only the physical fatigue scale was found to be a significant predictor. Among the psychological variables, state anxiety reigned as the most significant variable and there was a trend for evaluative 
Table 2

Group differences on measures of fatigue, depression, anxiety, self-efficacy, locus of control, coping, and personality

\begin{tabular}{|c|c|c|c|c|}
\hline Variable & $\begin{array}{l}\text { Considering }(\mathrm{N}=20) \\
(\mathrm{N}=20) \text { Mean }(\mathrm{S} . \mathrm{D})\end{array}$ & $\begin{array}{c}\text { Staying }(\mathrm{N}=20) \\
(\mathrm{N}=20) \text { Mean (S.D. })\end{array}$ & $t$-test or $\chi^{2}$, sig. & $d$ \\
\hline MFIS Cognitive Fatigue & $23.00(8.65)$ & $16.25(7.95)$ & $t=2.57, p=0.014$ & $\overline{0.81}$ \\
\hline MFIS Physical Fatigue & $23.60(5.94)$ & $15.20(7.11)$ & $t=4.05, p<0.001$ & 1.28 \\
\hline MFIS Psychosocial Fatigue & $4.70(1.59)$ & $3.15(1.63)$ & $t=3.04, p=0.004$ & 0.96 \\
\hline MFIS Total Fatigue & $51.30(14.59)$ & $34.60(15.42)$ & $t=3.52, p=0.001$ & 1.11 \\
\hline CMDI Mood & $27.60(11.24)$ & $21.65(9.02)$ & $t=1.85, p=0.073$ & \\
\hline CMDI Evaluative & $21.60(7.94)$ & $17.15(5.09)$ & $t=2.11, p=0.043$ & 0.67 \\
\hline CMDI Vegetative & $38.10(10.65)$ & $32.55(9.52)$ & $t=1.74, p=0.090$ & \\
\hline CMDI Total & $87.30(26.60)$ & $71.35(20.13)$ & $t=2.14, p=0.039$ & \\
\hline STAI State Anxiety & $43.65(13.59)$ & $31.30(8.81)$ & $t=3.41, p=0.002$ & 1.08 \\
\hline STAI Trait Anxiety & $43.20(11.30)$ & $34.25(9.65)$ & $t=2.69, p=0.010$ & 0.85 \\
\hline General Self-efficacy & $29.20(3.25)$ & $31.95(3.82)$ & $t=-2.42, p=0.020$ & 0.78 \\
\hline MS Self-efficacy & $51.45(10.86)$ & $64.50(15.82)$ & $t=-3.04, p=0.004$ & 0.96 \\
\hline Locus of Control & $70.30(10.78)$ & $77.15(11.38)$ & $t=-1.95, p=0.058$ & \\
\hline COPE Positive Reinterpretation & $12.25(2.22)$ & $12.95(2.16)$ & $t=-1.01, p=0.319$ & \\
\hline COPE Mental Disengagement & $9.25(2.34)$ & $8.85(2.30)$ & $t=0.55, p=0.589$ & \\
\hline COPE Venting Emotions & $9.05(2.14)$ & $9.60(3.94)$ & $t=-0.55, p=0.587$ & \\
\hline COPE Instrumental Social Support & $11.75(2.24)$ & $12.25(2.63)$ & $t=-0.65, p=0.522$ & \\
\hline COPE Active Coping & $11.55(1.79)$ & $11.70(2.32)$ & $t=-0.23, p=0.820$ & \\
\hline COPE Denial & $5.80(2.17)$ & $5.40(1.70)$ & $t=0.65, p=0.520$ & \\
\hline COPE Religious Coping & $9.95(4.62)$ & $9.10(4.98)$ & $t=0.56, p=0.579$ & \\
\hline COPE Humor & $8.85(2.96)$ & $11.20(2.76)$ & $t=-2.60, p=0.013$ & 0.82 \\
\hline COPE Behavioral Disengagement & $7.50(2.31)$ & $6.10(1.65)$ & $t=2.21, p=0.033$ & 0.70 \\
\hline COPE Restraint & $10.45(2.52)$ & $10.15(1.46)$ & $t=0.46, p=0.649$ & \\
\hline COPE Use of Emotional Social Support & $10.90(2.94)$ & $11.60(3.44)$ & $t=-0.69, p=0.493$ & \\
\hline COPE Substance Use & $5.15(2.08)$ & $4.85(2.78)$ & $t=0.39, p=0.701$ & \\
\hline COPE Acceptance & $11.20(2.24)$ & $11.30(1.66)$ & $t=-0.16, p=0.873$ & \\
\hline COPE Suppression of Competing Activities & $10.25(1.92)$ & $9.60(2.14)$ & $t=1.01, p=0.318$ & \\
\hline COPE Planning & $12.40(1.85)$ & $12.55(2.31)$ & $t=-0.23, p=0.822$ & \\
\hline NEO Openness & $30.25(7.08)$ & $32.05(6.72)$ & $t=-0.83, p=0.414$ & \\
\hline NEO Conscientiousness & $32.10(7.72)$ & $31.95(8.67)$ & $t=0.06, p=0.954$ & \\
\hline NEO Extraversion & $24.75(6.50)$ & $30.60(6.95)$ & $t=-2.75, p=0.009$ & 0.87 \\
\hline NEO Agreeableness & $34.75(5.55)$ & $35.90(6.19)$ & $t=-0.62, p=0.540$ & \\
\hline NEO Neuroticism & $24.35(9.18)$ & $17.45(9.37)$ & $t=2.35, p=0.024$ & 0.74 \\
\hline
\end{tabular}

Note. MFIS = Modified Fatigue Impact Scale; CMDI = Chicago Multiscale Depression Inventory; STAI=State Trait Anxiety Inventory; $\mathrm{COPE}=$ The COPE Inventory; NEO = NEO-Five Factor Inventory -3.

symptoms of depression. The DMSES, a measure of MS specific self-efficacy was found to be the most significant predictor among the self-efficacy and LOC measures. With regard to personality, only extraversion was included in the final model. Finally, of the COPE variables, humor and behavioral disengagement were found to differentiate those considering leaving or reducing work hours from those staying employed (See Table 3).

A final logistic regression was subsequently conducted to determine the most salient predictors of individuals considering leaving or cutting back when compared to those staying employed. The variables found to be significant in the preceding six regression analyses were included (i.e., physical fatigue, evaluative symptoms, state anxiety, MS self-efficacy, extraversion, and use of humor and behavioral disengagement as a means of coping). In this final model, the most significant predictors among these six variables were humor and behavioral disengagement as a coping mechanism and fatigue, accounting for $44 \%$ of the variance (See Table 4 ).

\section{Discussion}

The present investigation aimed to examine factors beyond demographics and disease variables that may distinguish individuals with MS who are considering reducing work hours or leaving the workforce from those staying employed. It was found that fatigue, depressive symptoms, anxiety, self-efficacy, personality, and coping styles all play a role in differentiating these two groups. The greatest effect $(d=1.28)$ was observed for physical fatigue, which has long been purported to be a primary reason for individuals reducing hours or stopping work. However, such individuals also reported experiencing greater anxiety 
Table 3

Forward (Wald) stepwise logistic regressions predicting employment status

\begin{tabular}{|c|c|c|c|c|c|}
\hline & $\mathrm{B}$ & $\operatorname{Exp}(\beta)$ & Wald & sig. & Cox \& Snell $\mathrm{R}^{2}$ \\
\hline \multicolumn{6}{|l|}{ Independent Variable(s): } \\
\hline \multicolumn{6}{|l|}{ Fatigue (MFIS subscales) } \\
\hline \multicolumn{6}{|l|}{ Step 1} \\
\hline Physical Fatigue & -0.200 & 0.819 & 8.97 & 0.003 & 0.30 \\
\hline \multicolumn{6}{|c|}{ Independent Variable (s): Anxiety (STAI subscales) } \\
\hline B & $\operatorname{Exp}(\beta)$ & Wald & sig. Cox \& Snell R ${ }^{2}$ & & \\
\hline \multicolumn{6}{|l|}{ Step 1} \\
\hline State Anxiety & -0.100 & 0.904 & 7.12 & 0.008 & 0.23 \\
\hline \multicolumn{6}{|c|}{ Independent Variable(s): Depression (CMDI Subscales) } \\
\hline B & $\operatorname{Exp}(\beta)$ & Wald & sig. Cox \& Snell R ${ }^{2}$ & & \\
\hline \multicolumn{6}{|l|}{ Step 1} \\
\hline Evaluative & -0.116 & 0.891 & 3.49 & 0.062 & 0.11 \\
\hline \multicolumn{6}{|c|}{ Independent Variable(s): Self-efficacy (GSE), MS self-efficacy (DMSES), \& Locus of Control (IPIP-LOC) } \\
\hline B & $\operatorname{Exp}(\beta)$ & Wald & sig. Cox \& Snell R ${ }^{2}$ & & \\
\hline \multicolumn{6}{|l|}{ Step 1} \\
\hline MS Self-efficacy & 0.088 & 1.09 & 8.00 & 0.005 & 0.25 \\
\hline \multicolumn{6}{|c|}{ Independent Variable(s): Personality (NEO-FFI) } \\
\hline B & $\operatorname{Exp}(\beta)$ & Wald & sig. Cox \& Snell R ${ }^{2}$ & & \\
\hline \multicolumn{6}{|l|}{ Step 1} \\
\hline Extraversion & 0.136 & 1.15 & 5.54 & 0.019 & 0.17 \\
\hline \multicolumn{6}{|c|}{ Independent Variable(s): Coping (COPE subscales) } \\
\hline B & $\operatorname{Exp}(\beta)$ & Wald & sig. Cox \& Snell R ${ }^{2}$ & & \\
\hline \multicolumn{6}{|l|}{ Step 1} \\
\hline Humor & 0.292 & 1.34 & 5.29 & 0.021 & 0.15 \\
\hline \multicolumn{6}{|l|}{ Step 2} \\
\hline Humor & 0.383 & 1.47 & 6.90 & 0.009 & \\
\hline Beh. Disengagement & -0.512 & 0.599 & 5.67 & 0.017 & 0.29 \\
\hline
\end{tabular}

Table 4

Comprehensive forward (Wald) stepwise logistic regression predicting employment status

\begin{tabular}{lrlllc}
\hline & B & Exp $(\beta)$ & Wald & sig. & Cox \& Snell R \\
\hline Step 1 & & & & & \\
$\quad$ Physical Fatigue & -0.200 & 0.819 & 8.97 & 0.003 & 0.30 \\
$\begin{array}{l}\text { Step 2 } \\
\quad \text { Physical Fatigue }\end{array}$ & -0.195 & 0.823 & 8.10 & 0.004 & \\
$\quad$ Humor & 0.295 & 1.34 & 3.51 & 0.061 & 0.37 \\
Step 3 & & & & & \\
$\quad$ Physical Fatigue & -0.181 & 0.834 & 6.37 & 0.012 & \\
$\quad$ Humor Beh. & 0.363 & 1.44 & 4.51 & 0.034 & \\
$\quad$ Disengagement & -0.478 & 0.620 & 3.64 & 0.056 & 0.44 \\
\hline
\end{tabular}

and more negative self-evaluative symptoms, as well as reporting lower levels of general and MS-specific self-efficacy, with effect sizes ranging from 0.67 to 1.08. The finding that such individuals are prone to negative affect and feel as if they have less selfefficacy or control over their illness, or in their lives in general, is a significant finding. Self-efficacy has been proven to be a significant predictor of various outcomes in MS including health status [41], adherence to treatment [42], disease management [43], adjustment [44], physical and social functioning [45], and physical activity and health-related quality of life in MS [46]. Thus, it is possible that an individual's perceived self-efficacy may mediate the relationship between disease factors and employment status, beyond disease variables. Individuals with high selfefficacy, regardless of disability level may feel that they can manage and control the impact of their MS and subsequent impact on day-to-day functioning such as employment. Such individuals may also feel that they can tackle the challenges they face in the workplace and find ways to manage expectations, seek help or accommodations, or more generally, simply seek solutions to problems in the workplace as this is a principal aspect of self-efficacy. Such findings regarding the role of self-efficacy and employment 
are also important given that there are several investigations that have shown that self-efficacy can be improved. For example, wellness programs [47], cognitive behavioral interventions [48], and fatigue management programs [49] have all been shown to result in improved levels of self-efficacy. Given the findings of the present study, assessment of one's selfefficacy and potential intervention to improve it may result in better employment outcomes.

The present findings also suggests that coping style is an important factor, with individuals staying employed utilizing humor more often and those considering cutting back or leaving describing greater utilization of behavioral disengagement. The use of negative or emotion-focused coping such as behavioral disengagement has consistently been shown to be related to poorer adjustment in MS [50], which may account for individuals feeling they must reduce hours or leave work completely. Research has shown that the majority of adjustment takes place within the first 10 years of diagnosis, with reports of lower depression [51] and greater self-concept following this critical period [52]. When looking at the considering group, it should be noted that the average disease duration was approximately five years, a fairly early tenure with MS in which many are likely still in the process of adjusting to a variable and unpredictable disease. It is even more noteworthy that while the range of years of diagnosis of the considering group was one to 22 years, $50 \%$ of the sample was diagnosed within the past three years and $70 \%$ within the past five years. In fact, only three individuals in the considering group were diagnosed more than 10 years ago $(11,17$, and 22 years). This is in contrast to the larger, employed group in this sample (prior to matching procedures that reduced the group size from 89 to 20), which had a mean disease duration of nine years with $55 \%$ of the sample having a disease duration greater than nine years. If simply comparing the two groups, it is striking that $50 \%$ of the considering group were within three years of diagnosis and 55\% of the staying employed group were diagnosed nine or more years ago; a time at which they may have adjusted to their diagnosis and disease. While it has been shown that disease duration and a progressive course are predictive of leaving the workforce, this data argues against disease progression and greater impairment as primary reasons for people leaving the workforce. It may be that individuals with longer disease duration have adjusted to their illness and perhaps have more perceived certainty and associated self-efficacy in dealing with their illness that allows them to remain employed. Present findings suggest that those considering reducing their hours/leaving work in this sample are perhaps having a difficult time adjusting to this illness as they are early in the disease course, are more depressed and anxious, and report having lower self-efficacy. Such findings suggest that early intervention, as opposed to later, may assist individuals with MS staying employed when the factors accounting for the decision are more related to person-specific factors such as coping and less to do with the disease and associated impairment, per se. This new conceptualization of when and for who early intervention may be warranted is the primary aim on the present investigation and it is hoped that these findings highlight the importance of assessing these factors when making employment decisions with patients, particularly early on in the disease process.

Finally, individuals who were considering cutting back/leaving endorsed lower levels of extraversion and this was found to be a significant predictor of employment status. Individuals also reported higher levels of neuroticism. As stated earlier, this synergistic combination of high neuroticism and low extraversion has been described as the "Type D or Distressed" personality. The finding that the considering group fits this pattern and report more depression and anxiety raises concern that such individuals may have significant health and social risks in addition to being at risk for unemployment. The fact that they are considering leaving work may be a red flag for graver concerns and potentially poorer overall prognosis. Moreover, given the impact unemployment can have on health and overall quality of life, these individuals are vulnerable to further mental and physical decline once out of work. It is thus imperative that these factors be assessed when individuals are in the process of making work determinations.

While these preliminary data are certainly compelling, there are certain limitations that temper the conclusions from this study. For one, a larger sample size is preferable. Given that this work is only preliminary, we suspect that once a larger sample of "considering" individuals are identified we will be able to not only obtain larger effect sizes, but will be able to model these factors in a more comprehensive manner to derive odds ratios for these constructs. Given the small sample at this time, we also do not have variability in disease course. In fact, all 40 participants have a relapsing-remitting course. Inclusion of individuals with a progressive course would render study findings more generalizable. Related to this 
is the lack of a measure of disease severity such as the Expanded Disability Status Scale (EDSS). Given that this was a national survey study, we have to rely on patients' neurologists to supply relevant medical information. Many did not report doing an EDSS or when done, may have been too far from the date of study to be reliable. Finally, we do not have cognitive test data on those individuals that we did not see in person. Given the proven validity of the Symbol Digit Modalities Test (SDMT) as the sole measure consistently predicting employment status [18] we have revised the study to now include an online version of the SDMT and expect that such data will greatly enhance this study.

In sum, the preliminary data of this study sheds light on the fact that there are a multitude of factors that need to be taken into account when making important decisions regarding employment in MS. These factors are certainly not limited to demographics and disease variables, despite them being the most studied to date. Further investigations should include more person-specific factors - both for identifying factors accountable for leaving as well as maintaining employment. For instance, based on present findings, the use of humor as a means of coping may be serving as a buffer and helping people manage their illness and stay employed. Thus, it may be beneficial to incorporate the use of humor and similar positive means of coping into therapeutic interventions. It is also hoped that these study findings alert practitioners to the importance of assessing these factors in practice when making decisions with their patients regarding work. Having an open dialogue regarding these factors and their potential contribution to work difficulty seems just as necessary as discussing disease factors. Effective communication of such may also result in more appropriate interventions and in turn, maintenance of employment and subsequent quality of life, which is the ultimate goal.

\section{Conflict of interest}

The authors have no conflict of interest or disclosures pertaining to this manuscript.

\section{Funding}

This work was funded by the National Institutes of Health NCMRR K23HD069494.

\section{References}

[1] Preiningerova J, Bomprezzi R, Vollmer TL, Waxman SG. Multiple Sclerosis. eLS 2009.

[2] NMSS. MS-Prevalence [Available from: http://www. nationalmssociety,org/About-the-Society/MS-Prevalence

[3] Harbo HF, Gold R, Tintoré M. Sex and gender issues in multiple sclerosis. Therapeutic Advances in Neurological Disorders 2013;6(4):237-48.

[4] Shnek ZM, Foley FW, LaRocca NG, Smith CR, Halper J. Psychological predictors of depression in multiple sclerosis. Neurorehabilitation and Neural Repair 1995;9(1): 15-23.

[5] Julian LJ, Vella L, Vollmer T, Hadjimichael O, Mohr DC. Employment in multiple sclerosis. Journal of Neurology 2008;255(9):1354-60.

[6] Roessler RT, Rumrill Jr PD. Multiple sclerosis and employment barriers: A systemic perspective on diagnosis and intervention. Work (Reading, Mass) 2002;21(1):17-23.

[7] Uccelli MM, Specchia C, Battaglia M, Miller D. Factors that influence the employment status of people with multiple sclerosis: A multi-national study. Journal of Neurology 2009;256(12):1989-96.

[8] Simmons RD, Tribe KL, McDonald EA. Living with multiple sclerosis: Longitudinal changes in employment and the importance of symptom management. Journal of Neurology 2010;257(6):926-36

[9] Pompeii LA, Moon SD, McCrory DC. Measures of physical and cognitive function and work status among individuals with multiple sclerosis: A review of the literature. Journal of Occupational Rehabilitation 2005;15(1):69-84.

[10] LaRocca N, Kalb R, Kendall P, Scheinberg L. The role of disease and demographic factors in the employment of patients with multiple sclerosis. Archives of Neurology 1982;39(4):256.

[11] LaRocca N, Kalb R, Scheinberg L, Kendall P. Factors associated with unemployment of patients with multiple sclerosis. Journal of Chronic Diseases 1985;38(2):203-10.

[12] O'Connor RJ, Cano SJ, i Torrenta LR, Thompson AJ, Playford ED. Factors influencing work retention for people with multiple sclerosis. Journal of Neurology 2005;252(8): 892-6.

[13] Smith MM, Arnett PA. Factors related to employment status changes in individuals with multiple sclerosis. Multiple Sclerosis 2005;11(5):602-9.

[14] Morrow SA, Drake A, Zivadinov R, Munschauer F, Weinstock-Guttman B, Benedict RH. Predicting loss of employment over three years in multiple sclerosis: Clinically meaningful cognitive decline. The Clinical Neuropsychologist 2010;24(7):1131-45.

[15] Dyck I, Jongbloed L. Women with multiple sclerosis and employment issues: A focus on social and institutional environments. Canadian Journal of Occupational Therapy 2000;67(5):337-46.

[16] Edgley K, Sullivan MJ, Dehoux E. A survey of multiple sclerosis: II. Determinants of employment status. Canadian Journal of Rehabilitation 1991.

[17] Strober LB, Christodoulou C, Benedict RH, Westervelt HJ, Melville P, Scherl WF, et al. Unemployment in multiple sclerosis: The contribution of personality and disease. Multiple Sclerosis Journal 2012;18(5):647-53.

[18] Strober L, Chiaravalloti N, Moore N, DeLuca J. Unemployment in multiple sclerosis (MS): Utility of the MS Functional Composite and cognitive testing. Multiple Sclerosis Journal 2013;18(5):6. 
[19] Schiavolin S, Leonardi M, Giovannetti AM, Antozzi C, Brambilla L, Confalonieri $\mathrm{P}$, et al. Factors related to difficulties with employment in patients with multiple sclerosis: A review of 2002-2011 literature. International Journal of Rehabilitation Research 2013;36(2):105-11.

[20] Rätsep T, Kallasmaa T, Pulver A, Gross-Paju K. Personality as a predictor of coping efforts in patients with multiple sclerosis. Multiple Sclerosis 2000;6(6):397-402.

[21] Connor-Smith JK, Flachsbart C. Relations between personality and coping: A meta-analysis. Journal of Personality and Social Psychology 2007;93(6):1080.

[22] Kern ML, Friedman HS. Why Do Some People Thrive While Other Succumb to Disease and Stagnation? Personality, Social Relations, and Resilience: Cambridge, UK, Cambridge University Press; 2010.

[23] Russo J, Katon W, Lin E, Von Korff M, Bush T, Simon G, et al. Neuroticism and extraversion as predictors of health outcomes in depressed primary care patients. Psychosomatics 1997;38(4):339-48.

[24] Lahey BB. Public health significance of neuroticism. American Psychologist 2009;64(4):241.

[25] Hampson SE, Friedman HS. Personality and health: A lifespan perspective; 2008.

[26] Denollet J, Sys SU, Brutsaert DL. Personality and mortality after myocardial infarction. Psychosomatic Medicine 1995;57(6):582-91.

[27] Denollet J, Rombouts H, Gillebert T, Brutsaert D, Sys S, Stroobant N. Personality as independent predictor of longterm mortality in patients with coronary heart disease. The Lancet 1996;347(8999):417-21.

[28] Denollet J, Brutsaert DL. Personality, disease severity, and the risk of long-term cardiac events in patients with a decreased ejection fraction after myocardial infarction. Circulation 1998;97(2):167-73.

[29] Ginting H, van de Ven M, Becker ES, Näring G. Type D personality is associated with health behaviors and perceived social support in individuals with coronary heart disease. Journal of Health Psychology 2014:1359105314536750.

[30] Staniute M, Brozaitiene J, Burkauskas J, Kazukauskiene N, Mickuviene N, Bunevicius R. Type D personality, mental distress, social support and health-related quality of life in coronary artery disease patients with heart failure: A longitudinal observational study. Health and Quality of Life Outcomes 2015;13(1):1.

[31] Merkelbach S, König J, Sittinger H. Personality traits in multiple sclerosis (MS) patients with and without fatigue experience. Acta Neurologica Scandinavica 2003;107(3):195-201.

[32] Harris M, Harris E, Shortus T. How do we manage patients who become unemployed? The Medical Journal of Australia 2010;192(2):4.

[33] Fisk JD, Ritvo PG, Ross L, Haase DA, Marrie TJ, Schlech WF. Measuring the functional impact of fatigue: Initial validation of the fatigue impact scale. Clinical Infectious Diseases 1994;18(Supplement 1):S79-S83.

[34] Nyenhuis DL, Luchetta T. The development, standardization, and initial validation of the Chicago Multiscale Depression Inventory. Journal of Personality Assessment 1998;70(2):386-401.

[35] Spielberger CD, Gorsuch RL. State-trait anxiety inventory for adults: Manual, instrument, and scoring guide: Mind Garden, Incorporated; 1983.
[36] Costa PT, McCrae RR. Neo PI-R professional manual; 1992.

[37] Carver CS, Scheier MF, Weintraub JK. Assessing coping strategies: A theoretically based approach. Journal of Personality and Social Psychology 1989;56(2):267.

[38] Schwarzer R, Jerusalem M. Generalized self-efficacy scale. Measures in Health Psychology: A User's Portfolio Causal and Control Beliefs 1995;1:35-7.

[39] Amtmann D, Bamer AM, Cook KF, Askew RL, Noonan VK, Brockway JA. University of Washington self-efficacy scale: A new self-efficacy scale for people with disabilities. Arch Phys Med Rehabil 2012;93(10):1757-65.

[40] Goldberg LR, Johnson JA, Eber HW, Hogan R, Ashton $\mathrm{MC}$, Cloninger $\mathrm{CR}$, et al. The international personality item pool and the future of public-domain personality measures. Journal of Research in Personality 2006;40(1):84-96.

[41] Riazi A, Thompson A, Hobart J. Self-efficacy predicts self-reported health status in multiple sclerosis. Multiple Sclerosis 2004;10(1):61-6.

[42] Mohr DC, Boudewyn AC, Likosky W, Levine E, Goodkin DE. Injectable medication for the treatment of multiple sclerosis: The influence of self-efficacy expectations and infection anxiety on adherence and ability to self-inject. Annals of Behavioral Medicine 2001;23(2):125-32.

[43] Eccles FJ, Simpson J. A review of the demographic, clinical and psychosocial correlates of perceived control in three chronic motor illnesses. Disabil Rehabil 2011;33(1314):1065-88.

[44] Wassem R. Self-efficacy as a predictor of adjustment to multiple sclerosis. Journal of Neuroscience Nursing 1992;24(4):224-9.

[45] Schmitt MM, Goverover Y, DeLuca J, Chiaravalloti N. Selfefficacy as a predictor of self-reported physical, cognitive, and social functioning in multiple sclerosis. Rehabilitation Psychology 2014;59(1):27.

[46] Motl RW, McAuley E, Snook EM. Physical activity and quality of life in multiple sclerosis: Possible roles of social support, self-efficacy, and functional limitations. Rehabilitation Psychology 2007;52(2):143.

[47] $\mathrm{Ng} \mathrm{A}$, Kennedy P, Hutchinson B, Ingram A, Vondrell S, Goodman T, et al. Self-efficacy and health status improve after a wellness program in persons with multiple sclerosis. Disabil Rehabil 2013;35(12):1039-44.

[48] Graziano F, Calandri E, Borghi M, Bonino S. The effects of a group-based cognitive behavioral therapy on people with multiple sclerosis: A randomized controlled trial. Clinical Rehabilitation 2013:0269215513501525.

[49] Thomas P, Thomas S, Kersten P. One year follow-up of a prahmatic multi-centre randomized controlled trial of a group-based fatigue management programme (FACETS) for people with multiple sclerosis. BioMedCentral Neurology 2014;14:109.

[50] Jean VM, Paul RH, Beatty WW. Psychological and neuropsychological predictors of coping patterns by patients with multiple sclerosis. Journal of Clinical Psychology 1999;55(1):21-6.

[51] Chwastiak L, Ehde DM, Gibbons LE, Sullivan M, Bowen JD, Kraft GH. Depressive symptoms and severity of illness in multiple sclerosis: Epidemiologic study of a large community sample. American Journal of Psychiatry 2002;159(11):6.

[52] Matson RR, Brooks NA. Adjusting to multiple sclerosis: An exploratory study. Soc Sci Med 1977;11(4):245-50. 